Journal of

Information Systems Engineering

and Business Intelligence

Vol.5, No.2, October 2019

Available online at: http://e-journal.unair.ac.id/index.php/JISEBI

\title{
Fertilizer Production Planning Optimization Using Particle Swarm Optimization-Genetic Algorithm
}

\author{
1)Universitas Islam Darul Ulum Lamongan, Indonesia \\ Jalan Airlangga 3 Sukodadi, Lamongan \\ 1)dinitarahmalia@gmail.com \\ 2)Universitas Nahdlatul Ulama Surabaya, Indonesia \\ Jalan Jemursari 59, Surabaya \\ 2)teguh@unusa.ac.id \\ 3)Universitas Muhammadiyah Malang, Indonesia \\ Jalan Raya Tlogomas 246, Malang \\ ${ }^{3)}$ thomy@umm.ac.id
}

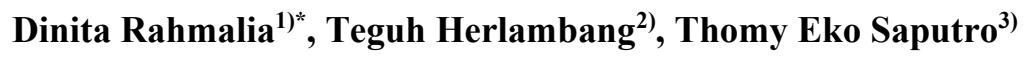

Article history:

Received 1 February 2019

Revised 31 July 2019

Accepted 31 July 2019

Available online 28 October 2019

\section{Keywords:}

Constrained Optimization, Genetic Algorithm, Linear Programming, Particle Swarm Optimization, Production Planning

\section{Abstract}

Background: The applications of constrained optimization have been developed in many problems. One of them is production planning. Production planning is the important part for controlling the cost spent by the company.

Objective: This research identifies about production planning optimization and algorithm to solve it in approaching. Production planning model is linear programming model with constraints : production, worker, and inventory.

Methods: In this paper, we use heurisitic Particle Swarm Optimization-Genetic Algorithm (PSOGA) for solving production planning optimization. PSOGA is the algorithm combining Particle Swarm Optimization (PSO) and mutation operator of Genetic Algorithm (GA) to improve optimal solution resulted by PSO. Three simulations using three different mutation probabilies : 0, 0.01 and 0.7 are applied to PSOGA. Futhermore, some mutation probabilities in PSOGA will be simulated and percent of improvement will be computed.

Results: From the simulations, PSOGA can improve optimal solution of PSO and the position of improvement is also determined by mutation probability. The small mutation probability gives smaller chance to the particle to explore and form new solution so that the position of improvement of small mutation probability is in middle of iteration. The large mutation probability gives larger chance to the particle to explore and form new solution so that the position of improvement of large mutation probability is in early of iteration.

Conclusion: Overall, the simulations show that PSOGA can improve optimal solution resulted by PSO and therefore it can give optimal cost spent by the company for the planning.

\section{INTRODUCTION}

The applications of constrained optimization have been developed in many problems such as transportation problem [1], production problem [2], supply chain model [3], scheduling optimization [4], and so on. One of constrained optimization is production planning. Production planning is the important part for controlling the cost spent by the company. Production planning which is used in this research is the case study of fertilizer production. In Indonesia having fertile soil, there are some farmers because the demand of food. Because of agriculture production demands, then fertilizer manufacturer produces fertilizer and distributes to farmers. In the production process, there are several costs raised and manufacturer must arrange the planning for revenue and several costs. Therefore this research identifies about production planning optimization and algorithm to solve it in approaching.

\footnotetext{
${ }^{*}$ Corresponding author
} 
Production planning model is linear programming model with constraints consisting of production, worker, and inventory. Linear programming as optimization problem can be solved by exact method like simplex method and if the solutions are integer then branch and bound and cutting plane method are required [5],[6]. Heuristic methods like Genetic Algorithm (GA) [1], Particle Swarm Optimization (PSO) [7],[8],[9],[10], Artificial Bee Colony (ABC) [11], Firefly Algorithm (FA) [2], Simulated Annealing [12] have applied in many linear programming problem. In constrained optimization using heuristic methods, approaching of new solution must satisfy the given constraints. The satisfication of constraints can be done by modified new solution [7], penalty technique [9], or goal programming [13].

Genetic Algorithm (GA) was discovered by Goldberg at 1989 [14]. GA works by natural selection process mechanism in chromosomes. Some processes of GA are initialization chromosome population, crossover, mutation, and selection chromosome [15]. Particle Swarm Optimization (PSO) was discovered by Kennedy and Eberhart in 1995. PSO is inspired by the behavior of flocks of birds or fishes with individual is called particle and the population is called a swarm [16].

In previous research, production planning optimization has been done by exact method like simplex method because the model of production planning optimization is linear in objective function and the constraints. Beside of exact method, heuristic methods have been done for approaching optimal solution [2]. However, the heuristic methods in previous research do not introduce the improvement of optimal solution.

In this paper, we use heuristic like Particle Swarm Optimization-Genetic Algorithm (PSOGA) for solving production planning optimization. PSOGA is the algorithm combining PSO and mutation operator of GA to improve optimal solution resulted by PSO. There are many literatures where either PSO or GA can be combined with standard algorithm to improve optimal solution resulted by standard algorithm as : in the researches [7] and [8] explaining about the combining PSO and GA for the transportation problem, in research [13] explaning about the combining Ant Colony Optimization (ACO) and GA for goal programming, in research [3] explaining about the combining PSO and GA for the supply chain model, in research [17] explaining about the combining PSO and Neural Network (NN) for forecasting the data, in research [18] explaining about the combining ACO and GA for the optimization problem.

In this research, data used for production planning optimization are obtained from annual report of one of the fertilizer manufacturer company in Gresik, East Java, Indonesia during 6 periods i.e. 2011, 2012, 2013, 2014, 2015, and 2016. From the data, we can contruct mathematical model of production planning with some constraints : production, worker, and inventory. PSO algorithm satisfying constraints production, worker, and inventory can be constructed. The results are minimum cost spent by the company as optimal solution in approaching.

In this proposed method, mutation operator is inserted to PSO algorithm to improve optimal solution. PSOGA is applied by three different mutation probabilities such as $0,0.01$, and 0.7 for comparison. Futhermore, some mutation probabilities in PSOGA will be simulated and percent of improvement will be computed. Improved optimal solutions are obtained so that PSOGA algorithm is smaller and better than PSO algorithm.

\section{LITERATURE REVIEW}

\section{A. Mathematical Model of Production Planning}

Production planning optimization is minimization of cost spent by company as in equation (1) with constraints consisting of production, worker, and inventory as in equation (2), equation (3), equation (4) respectively. Mathematical model of production planning can be constructed as follows [2],[19]:

$$
\min \sum_{t=1}^{T} C_{t}^{P} P_{t}+C_{t}^{W} W_{t}+C_{t}^{H} H_{t}+C_{t}^{L} L_{t}+C_{t}^{I} I_{t}
$$

Subject to :

$$
\begin{aligned}
& P_{t} \leq n_{t} W_{t}, \quad t=1,2, \ldots, T \\
& W_{t}=W_{t-1}+H_{t}-L_{t}, \quad t=1,2, \ldots, T \\
& I_{t}=I_{t-1}+P_{t}-D_{t}, \quad t=1,2, \ldots, T \\
& P_{t}, W_{t}, H_{t}, L_{t}, I_{t} \geq 0, \quad t=1,2, \ldots, T
\end{aligned}
$$


with $T$ is the planning time, $D_{t}$ is the number of units demanded in time $t, n_{t}$ is the number of units produced by a worker in time $t, C_{t}^{P}$ is the production cost per unit in time $t, C_{t}^{W}$ is the worker cost in time $t, C_{t}^{H}$ is the hired worker cost in time $t, C_{t}^{L}$ is the fired worker cost in time $t, C_{t}^{I}$ is the inventory holding cost in time $t, P_{t}$ is the number of units produced in time $t, W_{t}$ is the number of workers available in time $t, H_{t}$ is the number of hired workers in time $t, L_{t}$ is the number of fired workers in time $t, I_{t}$ is the number of inventory in time $t$.

In the equation (2), the number of units produced limits the number of units produced by current workers. In the equation (3), the number of current workers is the function of previous workers, hired worker, and fired worker. In the equation (4), the number of current inventory is the function previous period inventory, the number of units produced, and the current demand. In the equation (5), the solutions must be positive and integer number.

\section{B. Particle Swarm Optimization (PSO)}

PSO was the optimization method discovered by Kennedy and Eberhart in 1995. PSO mimics the behavior of flocks of birds or fishes with individual is called particle and the population is called swarm. Each particle has initial position and velocity. When particle finds the source of food, the others will follow them based on particle velocity [20].

Based on behavior of flocks of birds or fishes, then standard PSO algorithm is given as in Fig. 1.

Initialize particle position $x_{i j}{ }^{k}(0), k=1,2, \ldots$, maxswarm

Initialize particle velocity $v_{i j}{ }^{k}(0), k=1,2, \ldots$, maxswarm

Set local best particle $p_{i j}{ }^{k}=x_{i j}{ }^{k}(0), k=1,2, \ldots$, maxswarm

Set global best particle $g_{i j}=\arg \min \left(f\left(p_{i j}{ }^{k}\right), k=1,2, \ldots\right.$ maxswarm $)$

Update particle along time $t$.

for $t=0: \max$

for $k=1:$ maxswarm

Compute the particle velocity $v_{i j}{ }^{k}(t+1)$ with $r_{1}$ and $r_{2}$ are random number between $(0,1)$, inertia weight $\omega=1$, and $c_{1}=c_{2}=2$

$$
v_{i j}{ }^{k}(t+1)=w v_{i j}{ }^{k}(t)+c_{1} r_{1}\left(p_{i j}{ }^{k}-x_{i j}{ }^{k}(t)\right)+c_{2} r_{2}\left(g_{i j}-x_{i j}{ }^{k}(t)\right)
$$

Update the particle position $x_{i j}{ }^{k}(t+1)$

$$
x_{i j}{ }^{k}(t+1)=x_{i j}{ }^{k}(t)+v_{i j}{ }^{k}(t+1)
$$

Compute the fitness of particle $f\left(x_{i j}{ }^{k}(t+1)\right)$

Update local best particle $p_{i j}{ }^{k}$

$$
p_{i j}{ }^{k}=\underset{x}{\arg \min }\left(f\left(x_{i j}{ }^{k}(0)\right), f\left(x_{i j}{ }^{k}(1)\right), \ldots, f\left(x_{i j}{ }^{k}(t)\right), f\left(x_{i j}{ }^{k}(t+1)\right)\right.
$$

End

Update global best particle $g_{i j}$

$$
g_{i j}=\underset{p}{\arg \min }\left(f\left(p_{i j}{ }^{k}\right), k=1,2, \ldots \text { maxswarm }\right)
$$




\section{Particle Swarm Optimization-Genetic Algorithm (PSOGA)}

Particle Swarm Optimization-Genetic Algorithm (PSOGA) is the algorithm combining Particle Swarm Optimization (PSO) with mutation operator of Genetic Algorithm (GA) for improving optimal solution [8]. Mutation operator of GA is inserted to PSO algorithm to produce new optimal solution based on mutation probability. Mutation process occurs when probability is less than mutation probability $p_{m}$. After mutation process is implemented in the current population, it will result new population for next iteration.

\section{METHODS}

\section{A. Initialization Population}

For the production planning problem, the particle as the decision variable is the matrix where the elements are : $P_{t}$ is the number of units produced in time $t, W_{t}$ is the number of workers available in time $t, H_{t}$ is the number of hired workers in time $t, L_{t}$ is the number of fired workers in time $t, I_{t}$ is the number of inventory in time $t$. The design of decision variable can be seen in equation (6).

$$
X^{k}=(P, W, H, L, I)=\left[\begin{array}{cccc}
P_{1} & P_{2} & \ldots & P_{T} \\
W_{1} & W_{2} & \ldots & W_{T} \\
H_{1} & H_{2} & \ldots & H_{T} \\
L_{1} & L_{2} & \ldots & L_{T} \\
I_{1} & I_{2} & \ldots & I_{T}
\end{array}\right]
$$

In the first step of PSOGA, we need to initialize the population of particle. The initialization of particle must satisfy constraints (2) - (5). In order to satisfy constraints, the initialization can be designed as in Fig. 2.

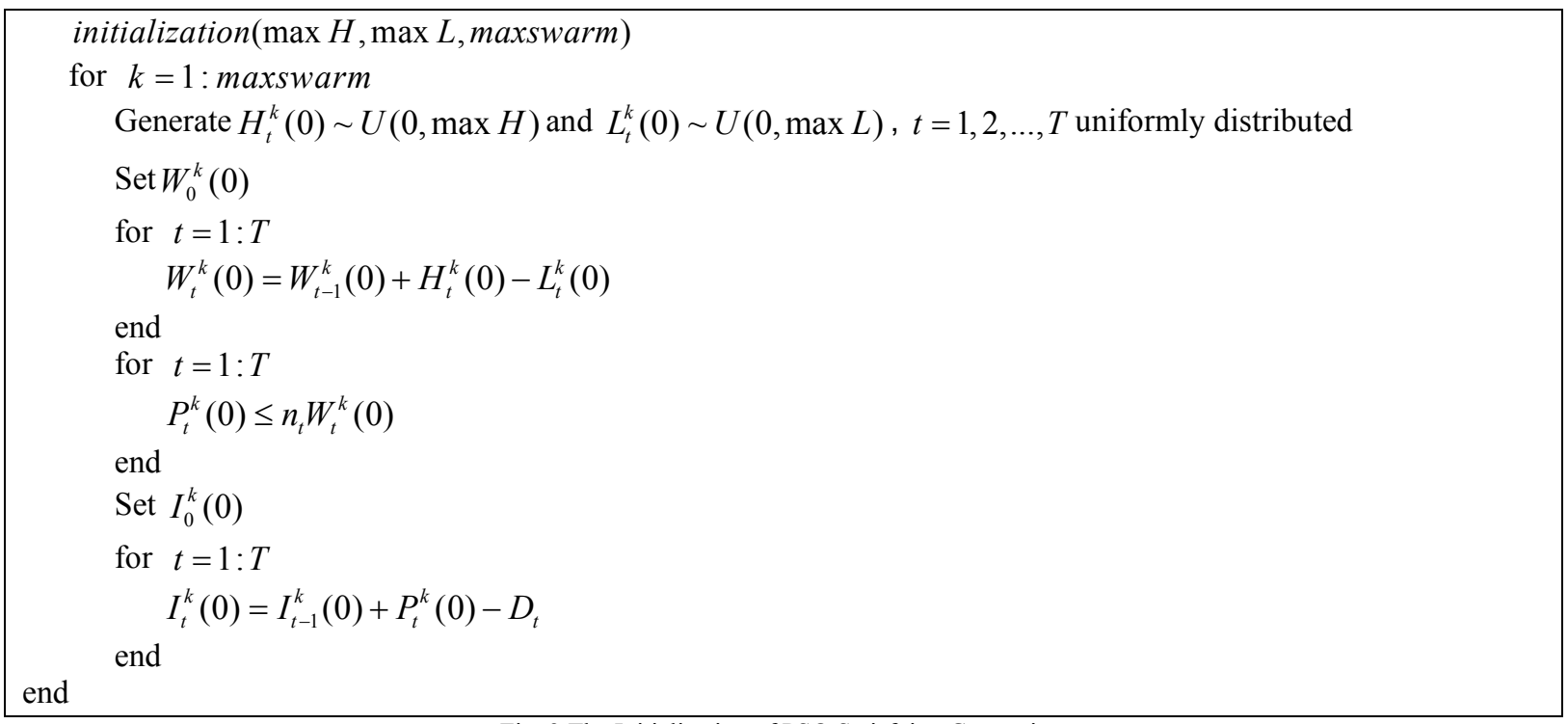

Fig. 2 The Initialization of PSO Satisfying Constraints

\section{B. Update the Particle}

We need to modify update the particle and velocity on PSO so that new particle can satisfy constraints in (2) - (5). The modification of update particle and velocity can be designed as in Fig. 3. 


\section{update $(X)$}

Update $v_{H}^{k}, \quad k=1,2, \ldots$, maxswarm, particle velocity of $H^{k}$ with $p_{H}^{k}$ is the its local best particle of hired worker and $g_{H}$ is the its global best particle of hired worker.

$$
v_{H}{ }^{k}(t+1)=w v_{H}{ }^{k}(t)+c_{1} r_{1}\left(p_{H}{ }^{k}-H^{k}(t)\right)+c_{2} r_{2}\left(g_{H}-H^{k}(t)\right)
$$

Update $H^{k}, k=1,2, \ldots$, maxswarm

$$
H^{k}(t+1)=H^{k}(t)+v_{H}{ }^{k}(t+1)
$$

Update $v_{L}^{k}, \quad k=1,2, \ldots$, maxswarm, particle velocity of $L^{k}$ with $p_{L}^{k}$ is the its local best particle of fired worker and $g_{L}$ is the its global best particle of fired worker.

$$
v_{L}^{k}(t+1)=w v_{L}^{k}(t)+c_{1} r_{1}\left(p_{L}^{k}-L^{k}(t)\right)+c_{2} r_{2}\left(g_{L}-L^{k}(t)\right)
$$

Update with $L^{k}, k=1,2, \ldots$, maxswarm

$$
L^{k}(t+1)=L^{k}(t)+v_{L}^{k}(t+1)
$$

For $W_{i}^{k}(t+1), P_{i}^{k}(t+1), I_{i}^{k}(t+1), i=1,2, \ldots, T$, do similar procedures as in initialization step so that constraints in equations $(2)-(5)$ are satisfied.

$$
\text { Fig. } 3 \text { The Update Particle of PSO Satisfying Constraints }
$$

\section{Mutation Operator}

Mutation operator is one of the operator used in Genetic Algorithm (GA). In GA, mutation process changes some unit of origin chromosome to create new chromosome depends on mutation probability $p_{m}$ [15]. Mutation operator can improve optimal solution which is resulted by PSO because mutation operator can find the new solution. Mutation operator must be designed to satisfy constraints (2) - (5). The algorithm of mutation operator can be constructed as in Fig. 4.

mutation $(X)$

Select hired worker $H_{t}, t=1,2, \ldots, T$

Determine the number of changed elements $1 \leq t \leq T$ randomly.

Change with new elements between $(0, \max H)$ uniformly distributed so that result new $H_{t}^{\prime}$

Select fired worker $L_{t}, t=1,2, \ldots, T$

Determine the number of changed elements $1 \leq t \leq T$ randomly.

Change with new elements between $(0, \max L)$ uniformly distributed so that result new $L_{t}^{\prime}$

For $W_{i}^{\prime}, P_{i}^{\prime}, I_{i}^{\prime}, i=1,2, \ldots, T$, do similar procedures as in initialization step so that constraints in equation (2) $-(5)$ are satisfied.

Fig. 4 The Mutation Particle Satisfying Constraints

\section{Overall Algorithm}

This method introduces the improvement of standard PSO or other heuristics in previous research. In addition, mutation operator as in Fig. 4 is inserted to PSO algorithm for improving optimal solution. This algorithm is called PSOGA as in Fig. 5. Mutation operator is inserted after the particle are updated. 


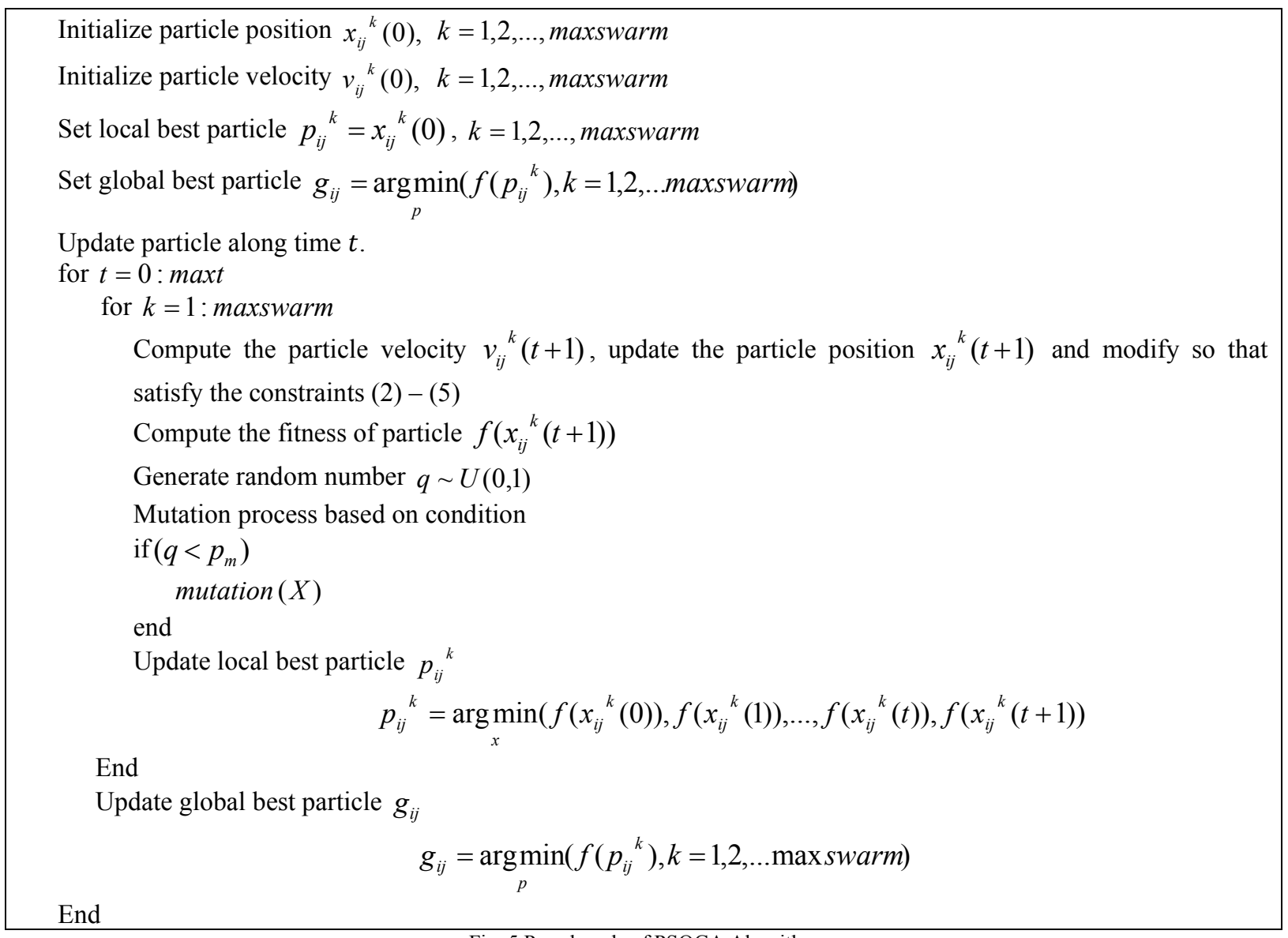

Fig. 5 Pseudocode of PSOGA Algorithm

\section{RESUlTS}

The method used in this research can be seen as diagram in Fig. 6 :

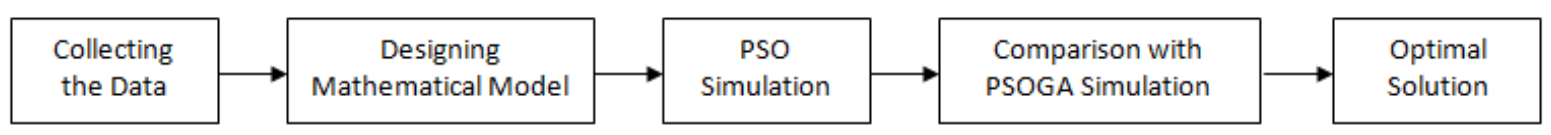

Fig. 6The Diagram of PSOGA Method

Data used in the simulations are obtained from one of the fertilizer manufacturer company in Gresik, East Java, Indonesia during 6 periods i.e. 2011, 2012, 2013, 2014, 2015, and 2016. From the data, we can make fertilizer production planning optimization. Table 1 shows cost per unit in each year which consists : production cost per unit $C_{t}^{P}$, worker cost $C_{t}^{W}$, hired worker cost $C_{t}^{H}$, fired worker cost $C_{t}^{L}$, and inventory holding $\operatorname{cost} C_{t}^{I}$, for each year $t=2011,2012,2013,2014,2015,2016$. Table 2 shows the number of units demanded for each period $D_{t}$ and the number of units produced by a worker for each period $n_{t}$ for each year $t=2011,2012,2013,2014,2015,2016$ 
TABLE 1

\begin{tabular}{ccccccc}
\multicolumn{7}{c}{ VALUE OF COST PER UNIT (IN MILLION RUPIAHS) } \\
\hline$C_{t}^{P}$ & $\mathbf{2 0 1 1}$ & $\mathbf{2 0 1 2}$ & $\mathbf{2 0 1 3}$ & $\mathbf{2 0 1 4}$ & $\mathbf{2 0 1 5}$ & $\mathbf{2 0 1 6}$ \\
$C_{t}^{W}$ & 4.00 & 4.54 & 5.17 & 5.33 & 5.71 & 5.33 \\
$C_{t}^{H}$ & 7 & 7 & 7 & 7 & 7 & 7 \\
$C_{t}^{L}$ & 4 & 4 & 4 & 4 & 4 & 4 \\
$C_{t}^{I}$ & 2 & 2 & 2 & 2 & 2 & 2 \\
\hline
\end{tabular}

TABLE 2

THE NUMBER OF UNITS DEMANDED (IN TONS) AND THE NUMBER OF UNITS PRODUCED BY A WORKER (IN TONS/WORKER)

\begin{tabular}{cccccc}
\multicolumn{7}{c}{ THE NUMBER OF UNITS DEMANDED (IN TONS) } & \multicolumn{1}{c}{ AND THE NUMBER OF UNITS PRODUCED BY A WORKER (IN TONS/WORKER) } \\
\hline & $\mathbf{2 0 1 1}$ & $\mathbf{2 0 1 2}$ & $\mathbf{2 0 1 3}$ & $\mathbf{2 0 1 4}$ & $\mathbf{2 0 1 5}$ \\
\hline$D_{t}$ & 4328630 & 5008571 & 5409669 & 5375396 & 5546783 \\
$n_{t}$ & 1060 & 1271 & 1249 & 1266 & 1285 \\
\hline
\end{tabular}

From the data obtained, we can contruct mathematical model of production planning with minimization of cost spent by company as in equation (1) and some constraints consisting of production as in equation (2), worker as in equation (3), and inventory as in equation (4). After the data are used in mathematical model of production planning optimization, PSO algorithm satisfying constraints (2), (3), (4) and (5) can be constructed as Fig. 1 with initialization particle as in Fig. 2 and update particle as in Fig. 3. The simulations are applied by Matlab. The results are minimum cost spent by the company in equation (1) as optimal solution in approaching.

PSOGA is applied by three different mutation probabilities : 0, 0.01, and 0.7 for comparison. Furthermore, some mutation probabilities in PSOGA will be simulated and percent of improvement will be computed. The simulations are also applied by Matlab. The results are minimum cost spent by the company in equation (1) as optimal solution in approaching and its improvement of PSO.

\section{A. Simulation with Mutation Probability is 0}

Fig. 7 shows the simulation of PSOGA on production planning optimization with mutation probability is 0 . In early time, the particle positions are chosen randomly. In the optimization process, position and velocity particle are updated so that fitness will decrease and converge. From the simulation, PSOGA simulation shows similar plot with PSO simulation and there is no improvement along iteration so that PSOGA with no mutation probability is similar to PSO with objective value in equation (1) as fitness is 214698345 million rupiahs.

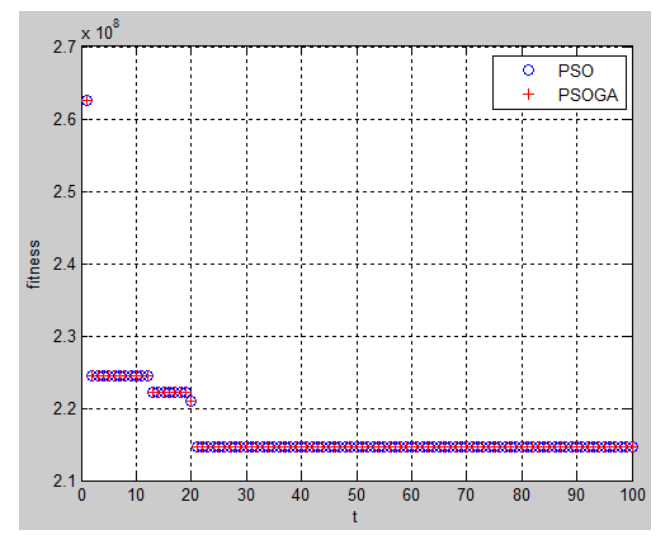

Fig. 7Optimization Result by PSOGA with Mutation Probability is 0

Decision variable as optimal solution in approaching of PSOGA with mutation probability is 0 can be seen in Table 3 where in the elements are $H_{t}$ is the number of hired workers in time $t, L_{t}$ is the number of fired workers in time $t, P_{t}$ is the number of units produced in time $t, W_{t}$ is the number of workers available in time $t, I_{t}$ is the number of inventory in time $t$. 
TABLE 3

\begin{tabular}{ccccccc}
\multicolumn{7}{c}{ OPTIMAL SOLUTION BY PSOGA WITH MUTATION PROBABILITY IS 0 } \\
\hline$H_{t}$ & $\mathbf{2 0 1 1}$ & $\mathbf{2 0 1 2}$ & $\mathbf{2 0 1 3}$ & $\mathbf{2 0 1 4}$ & $\mathbf{2 0 1 5}$ & $\mathbf{2 0 1 6}$ \\
\hline$L_{t}$ & 128 & 129 & 218 & 368 & 274 & 218 \\
$W_{t}$ & 296 & 224 & 234 & 3162 & 236 & 3044 \\
$P_{t}$ & 3179 & 3084 & 3068 & 3267430 & 3178487 & 3384140 \\
$I_{t}$ & 2712106 & 3298229 & 3206010 & 2939 & 2198380 & 225402 \\
\hline
\end{tabular}

\section{B. Simulation with Mutation Probability is 0.01}

Fig. 8 shows the simulation of PSOGA on production planning optimization with mutation probability is 0.01 . In early time, the particle positions are chosen randomly. In the optimization process, position and velocity particle are updated so that fitness will decrease and converge. From the simulation, because the mutation probability is relative small, there is improvement in the middle of iteration so that PSOGA gives smaller and better optimal solution than PSO with objective value in equation (1) as fitness is 210540703 million rupiahs.

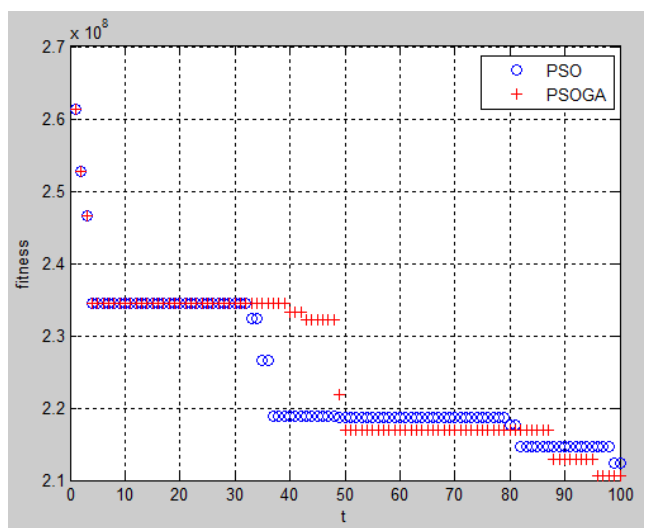

Fig. 8 Optimization Result by PSOGA with Mutation Probability is 0.01

Decision variable as optimal solution in approaching of PSOGA with mutation probability is 0.01 can be seen in Table 4 where in the elements are $H_{t}$ is the number of hired workers in time $t, L_{t}$ is the number of fired workers in time $t, P_{t}$ is the number of units produced in time $t, W_{t}$ is the number of workers available in time $t, I_{t}$ is the number of inventory in time $t$.

TABLE 4

\begin{tabular}{|c|c|c|c|c|c|c|}
\hline & 2011 & 2012 & 2013 & 2014 & 2015 & 2016 \\
\hline$H_{t}$ & 132 & 144 & 123 & 192 & 227 & 104 \\
\hline$L_{t}$ & 298 & 277 & 210 & 241 & 292 & 206 \\
\hline$W_{t}$ & 3181 & 3048 & 2961 & 2912 & 2847 & 2745 \\
\hline$P_{t}$ & 2774050 & 3150904 & 3012529 & 3267123 & 3438735 & 3223916 \\
\hline$I_{t}$ & 10650587 & 8792920 & 6395780 & 4287507 & 2179459 & 46257 \\
\hline
\end{tabular}

\section{Simulation with Mutation Probability is 0.7}

Fig. 9 shows the simulation of PSOGA on production planning optimization with mutation probability is 0.7 . In early time, the particle positions are chosen randomly. In the optimization process, position and velocity particle are updated so that fitness will decrease and converge. From the simulation, because the mutation probability is relative 
large, there is improvement in the early of iteration so that PSOGA gives smaller and better optimal solution than PSO with objective value in equation (1) as fitness is 210871781 million rupiahs.

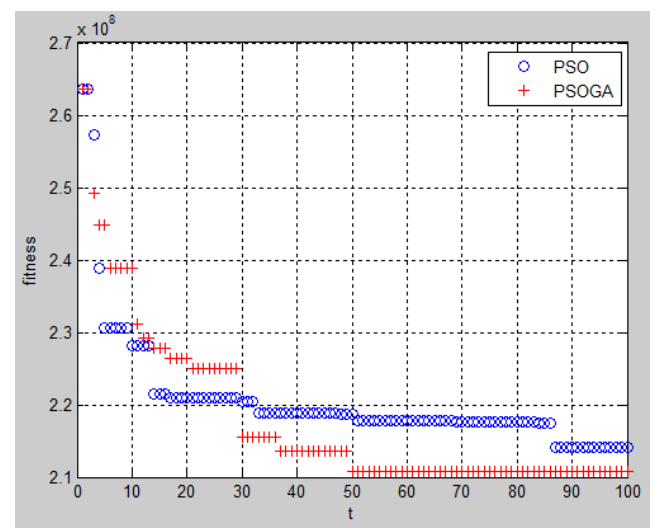

Fig. 9Optimization Result by PSOGA with Mutation Probability is 0.7

Decision variable as optimal solution in approaching of PSOGA with mutation probability is 0.7 can be seen in Table 5 where in the elements are $H_{t}$ is the number of hired workers in time $t, L_{t}$ is the number of fired workers in time $t, P_{t}$ is the number of units produced in time $t, W_{t}$ is the number of workers available in time $t, I_{t}$ is the number of inventory in time $t$.

TABLE 5

\begin{tabular}{|c|c|c|c|c|c|c|}
\hline & 2011 & 2012 & 2013 & 2014 & 2015 & 2016 \\
\hline$H_{t}$ & 119 & 158 & 104 & 174 & 248 & 328 \\
\hline$L_{t}$ & 251 & 244 & 260 & 228 & 235 & 121 \\
\hline$W_{t}$ & 3215 & 3129 & 2973 & 2919 & 2932 & 3139 \\
\hline$P_{t}$ & 2726575 & 3222682 & 3160912 & 3146478 & 3075325 & 3638297 \\
\hline$I_{t}$ & 10603112 & 8817223 & 6568466 & 4339548 & 1868090 & 149269 \\
\hline
\end{tabular}

\section{Simulations with Some Mutation Probabilities}

The comparison between PSO and PSOGA with some mutation probabilities can be seen in Table 6. The position of improvement of small mutation probability $\left(0.01 \leq p_{m} \leq 0.09\right)$ is in middle of iteration. The position of improvement of large mutation probability $\left(0.1 \leq p_{m} \leq 0.9\right)$ is in early of iteration (iteration $\left.=2\right)$. Mutation operator can improve optimal solution resulted byPSO to become smaller because mutation operator can explore the new solution. The small mutation probability gives smaller chance to the particle to explore and form new solution so that the position of improvement of small mutation probability is in middle of iteration. The large mutation probability gives larger chance to the particle to explore and form new solution so that the position of improvement of large mutation probability is in early of iteration. From the Table 6, we can see that PSOGA can improve optimal solution resulted by PSO with smaller and better value with percent improvement as in (7):

$$
\text { percent improvement }=\frac{(\text { best fitness PSO }- \text { best fitness PSOGA) }}{\text { best fitness PSO }} \times 100 \%
$$

with the average of overall percent improvement is 0.9738 percent. 
TABLE 6

\begin{tabular}{|c|c|c|c|c|c|c|}
\hline No & $\begin{array}{r}\text { Mutation } \\
\text { Probability }\end{array}$ & $\begin{array}{r}\text { Position of } \\
\text { Improvement } \\
\text { (of 100 iterations) }\end{array}$ & $\begin{array}{r}\text { Time Computation } \\
\text { (second) }\end{array}$ & $\begin{array}{r}\text { PSO Best } \\
\text { Fitness } \\
\left(\begin{array}{ll}\left.\mathbf{x} 10^{8}\right) \\
\end{array}\right.\end{array}$ & 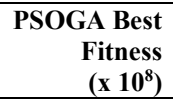 & \% Improvement \\
\hline 1 & 0.01 & 36 & 2.4382 & 2.1484 & 2.1352 & 0.6144 \\
\hline 2 & 0.02 & 27 & 2.1673 & 2.1341 & 2.1105 & 1.1059 \\
\hline 3 & 0.03 & 39 & 2.1483 & 2.1274 & 2.0900 & 1.7580 \\
\hline 4 & 0.04 & 21 & 2.2162 & 2.1362 & 2.1281 & 0.3792 \\
\hline 5 & 0.05 & 12 & 2.2381 & 2.1345 & 2.1129 & 1.0120 \\
\hline 6 & 0.06 & 8 & 2.2517 & 2.1504 & 2.1432 & 0.3348 \\
\hline 7 & 0.07 & 8 & 2.5633 & 2.1457 & 2.1052 & 1.8875 \\
\hline 8 & 0.08 & 7 & 2.3067 & 2.1617 & 2.1300 & 1.4664 \\
\hline 9 & 0.09 & 4 & 2.6065 & 2.1291 & 2.1072 & 1.0286 \\
\hline 10 & 0.1 & 6 & 2.2081 & 2.1632 & 2.1558 & 0.3421 \\
\hline 11 & 0.2 & 3 & 2.2912 & 2.1323 & 2.0849 & 2.2230 \\
\hline 12 & 0.3 & 2 & 2.6372 & 2.1624 & 2.1526 & 0.4532 \\
\hline 13 & 0.4 & 2 & 2.7390 & 2.1626 & 2.1439 & 0.8647 \\
\hline 14 & 0.5 & 2 & 2.8554 & 2.1408 & 2.1371 & 0.1728 \\
\hline 15 & 0.6 & 2 & 2.4766 & 2.1855 & 2.1783 & 0.3294 \\
\hline 16 & 0.7 & 2 & 2.7459 & 2.1456 & 2.1387 & 0.3216 \\
\hline 17 & 0.8 & 2 & 2.6268 & 2.202 & 2.1871 & 0.6767 \\
\hline 18 & 0.9 & 2 & 2.6740 & 2.2203 & 2.1635 & 2.5582 \\
\hline \multicolumn{3}{|c|}{ Average } & 2.4550 & 2.154567 & 2.133567 & 0.9738 \\
\hline
\end{tabular}

\section{DISCUSSION}

Three simulations using three different mutation probabilities are applied to PSOGA. From the first simulation with mutation probability is 0, PSOGA simulation shows similar plot with PSO simulation and there is no improvement along iteration so that PSOGA with no mutation probability is similar to PSO. From the second simulation with mutation probability is 0.01 , because the mutation probability is relative small, there is improvement in the middle of iteration so that PSOGA gives smaller and better optimal solution than PSO. From the third simulation with mutation probability is 0.7 , because the mutation probability is relative large, there is improvement in the early of iteration so that PSOGA gives smaller and better optimal solution than PSO. The small mutation probability gives smaller chance to the particle to explore and form new solution so that the position of improvement of small mutation probability is in middle of iteration. The large mutation probability gives larger chance to the particle to explore and form new solution so that the position of improvement of large mutation probability is in early of iteration.

\section{CONCLUSIONS}

Production planning optimization is one of constrained optimization with constraint production, worker, and inventory. Heuristic method like PSO has been applied in approaching optimal solution by modifying the particle position and particle velocity so that particle can satisfy the constraints. In this research, PSO is combined by mutation operator of GA. From the simulations, PSOGA can improve optimal solution of PSO and the position of improvement is also determined by mutation probability. The developments of this research are the products produced not only one product but also they can be multiple products so that new optimization model can be researched.

\section{ACKNOWLEDGMENTS}

High appreciation to the Ministry of Research, Technology and High Education (Kemenristekdikti), Republic of Indonesia for the Penelitian Dosen Pemula fund for the research conducted in the year 2019 .

\section{REFERENCES}

[1] D. Rahmalia, "Perbandingan Metode Analitik dan Metode Heuristik pada Optimisasi Masalah Transportasi Distribusi Semen," Prosiding Seminar Nasional Matematika dan Pembelajarannya, pp. 1164-1172, 2016

[2] D. Rahmalia and A.M. Rohmah, "Optimisasi Perencanaan Produksi Pupuk Menggunakan Firefly Algorithm," Jurnal Matematika MANTIK, vol. 4, no. 1, 2018

[3] R.J. Kuo and Y.S. Han, "A Hybrid of Genetic Algorithm and Particle Swarm Optimization for Solving Bi-Level Linear Programming Problem - A Case Study on Supply Chain Model," Applied Mathematical Modelling, vol. 35, pp. 3905-3917, 2011

[4] D. Rahmalia, K. Novianingsih and R. Hadianti, "Optimisasi Crew Pairing dengan Memodifikasi Jadwal Penerbangan," Tesis Magister Matematika ITB, 2013 
[5] F.S. Hiller and G.J. Lieberman, Introduction to Operations Research. New York: Mc Graw Hill, 2001

[6] H.A. Taha, Operation Research : An Introduction. New Jersey: Prentice Hall, 2007

[7] D. Rahmalia, "Particle Swarm Optimization-Genetic Algorithm (PSOGA) on Linear Transportation Problem," AIP Conference Proceeding, pp. (020030)1-12, 2017

[8] H. Huang and Z. Hao, Particle Swarm Optimization Algorithm for Transportation Problem, Shanghai: InTech, 2009

[9] D. Rahmalia, "Teknik Penalti pada Optimisasi Berkendala Menggunakan Particle Swarm Optimization," JMPM : Jurnal Matematika dan Pendidikan Matematika, vol. 3, no. 1, 2018

[10] A. Babazadeh, H. Poorzahedy and S. Nikoosokhan, "Application of Particle Swarm Optimization to Transportation Network Design Problem,” Journal of King Saud University-Science, vol. 23, pp. 293-300, 2011

[11] D. Rahmalia and T. Herlambang, "Optimisasi Masalah Transportasi Distribusi Semen Menggunakan Algoritma Artificial Bee Colony," Multitek Indonesia, vol. 11, no. 2, 2018

[12] J.J. Schneider and S. Kirkpatrick, Stochastic Optimization. Berlin: Springer, 2006

[13] D. Rahmalia, T.E. Saputro and T. Herlambang, "Goal Programming on Production Planning Using Ant Colony Optimization-Genetic Algorithm (ACOGA)," Proceeding $5^{\text {th }}$ International Conference on Research, Implementation, and Education of Mathematics and Science, 2018

[14] D. Goldberg, Genetic Algorithm in Search, Optimization, and Machine Learning. Massachusetts : Addison Wesley, 1989

[15] M. Gen and R. Cheng, Genetic Algorithm and Engineering Design. New York: John Wiley and Sons, 1997

[16] J. Kennedy and R.C. Eberhart, "Particle Swarm Optimization,” Proc. IEEE Int. Conf. Neural Networks, pp. 1942-1948, 1995

[17] D. Rahmalia and T. Herlambang, "Prediksi Cuaca Menggunakan Algoritma Particle Swarm Optimization-Neural Network (PSONN)," Prosiding Seminar Nasional Matematika dan Aplikasinya, pp. 41-48, 2017

[18] S. Singh, G.C. Dubey and R. Shrivastava, “Ant Colony Optimization Using Genetic Algorithms," International Journal of Theoretical and Applied Sciences, vol. 4,no. 1, pp. 48-51, 2012

[19] B. Techaroongruengkij, C. Prakasvudhisarn and P. Yenradee, "A PSO Based Goal Programming Approach to Aggregate Planning of Production, Workforce, and Pricing Strategy,"

[20] S.S. Rao, Engineering Optimization Theory and Practice. New Jersey: John Wiley and Sons, 2009 